\title{
HASIL DAN MUTU JAGUNG MANIS (ZEA MAYS SACCHARATA STURT) DENGAN PERLAKUAN PUPUK KANDANG AYAM DAN KALIUM
}

\author{
Muhammad Yusuf. $\mathrm{N}^{1}$
}

Email Author: myusufn.@unimal.ac.id

\begin{abstract}
ABSTRAK
Penelitian ini bertujuan untuk mengetahui pengaruh pupuk kandang ayam dan kalium terhadap hasil dan mutu jagung manis. Penelitian ini menggunakan Rancangan Acak Kelompok faktorial dengan 2 faktor perlakuan dan 3 ulangan. Faktor pertama adalah pupuk kandang ayam terdiri atas $\mathrm{A}_{0}(0 \mathrm{Kg} / \mathrm{ha}), \mathrm{A}_{1}(10 \mathrm{Kg} / \mathrm{ha}), \mathrm{A}_{2}(15 \mathrm{Kg} / \mathrm{ha})$ dan $\mathrm{A}_{3}(20$ $\mathrm{Kg} / \mathrm{ha})$. Faktor kedua adalah pupuk kalium terdiri dari $\mathrm{K}_{0}\left(0 \mathrm{Kg} \mathrm{K} \mathrm{K}_{2} \mathrm{O} / \mathrm{ha}\right), \mathrm{K}_{1}(90 \mathrm{Kg}$ $\left.\mathrm{K}_{2} \mathrm{O} / \mathrm{ha}\right), \mathrm{K}_{2}(120 \mathrm{Kg} \mathrm{K} 2 \mathrm{O} / \mathrm{ha})$, dan $\mathrm{K}_{3}\left(150 \mathrm{Kg} \mathrm{K}_{2} \mathrm{O} / \mathrm{ha}\right)$. Hasil penelitian menunjukkan bahwa pemberian pupuk kandang ayam dan kalium secara umum belum menunjukkan pengaruh yang signifikan terhadap peningkatan hasil dan mutu jagung manis. Kombinasi perlakuan $\mathrm{A}_{0} \mathrm{~K}_{2}$ menunjukkan hasil dan kualitas terbaik.
\end{abstract}

Kata Kunci: Pupuk Kandang Ayam, Pupuk Kalium, Jagung manis

ABSTRACT

The aim of this research was to know the effect of chicken manure and potassium on the yield and quality of sweet corn. The research used a Randomized Block Design Factorial with 2 factors and 3 replications. The first factor is chicken manure: $A_{0}(0 \mathrm{Kg} / \mathrm{ha}), \mathrm{A}_{1}(10$ $\mathrm{Kg} / \mathrm{ha}), \mathrm{A}_{2}(15 \mathrm{Kg} / \mathrm{ha})$ and $\mathrm{A}_{3}(20 \mathrm{Kg} / \mathrm{ha})$. The second one is potassium fertilizer: $\mathrm{K}_{0}(0$ $\mathrm{Kg} \mathrm{K} 2 \mathrm{O} / \mathrm{ha}), \mathrm{K}_{1}(90 \mathrm{Kg} \mathrm{K} 2 \mathrm{O} / \mathrm{ha}), \mathrm{K}_{2}\left(120 \mathrm{Kg} \mathrm{K}_{2} \mathrm{O} / \mathrm{ha}\right)$, and $\mathrm{K}_{3}\left(150 \mathrm{Kg} \mathrm{K}_{2} \mathrm{O} / \mathrm{ha}\right)$. The result research showed a not significant increased in the yield and quality of sweet corn. The combination of treatment $\mathrm{A}_{0} \mathrm{~K}_{2}$ gave the best yield and quality.

Keywords: Chicken Manure, Potassium Fertilizer, Sweet corn

\section{PENDAHULUAN}

Jagung manis merupakan tanaman pangan yang memiliki masa produksi yang relatif lebih cepat, bernilai ekonomis dan strategis. Sebagai salah satu komoditas unggulan, jagung manis mempunyai banyak kelebihan antara lain serat yang tidak terlalu liat sehingga menciptakan tekstur lebih nyaman dalam proses mengunyah, kadar gula tinggi dan nilai nutrisi yang lebih baik dibandingkan dengan jagung biasa. Jagung manis mempunyai kadar gula 4 8 kali lebih tinggi dari jagung biasa yakni mengandung $12-14 \%$ kadar gula, sedangkan jagung biasa hanya $2-4 \%$. Oleh sebab itu permintaan pasar terhadap komoditi ini cukup tinggi, tetapi produktivitas jagung manis belum mampu memenuhi permintaan tersebut.

Listyobudi (2011) menyatakan bahwa produktivitas jagung manis di Indonesia masih rendah bila dibandingkan dengan negara lainnya terutama Amerika Serikat dan Australia yang mampu menghasilkan $7-10$ ton/ha. Berdasarkan hasil penelitian Budiastuti et al., (2011) menunjukkan bahwa hasil jagung manis di Indonesia hanya mencapai 4-5 ton/ha.

Rendahnya produktivitas jagung manis di Indonesia menggambarkan bahwa penerapan teknologi budidaya

\footnotetext{
${ }^{1}$ Program Studi Agroekoteknologi Fakultas Pertanian Universitas Malikussaleh, Aceh Utara
} 
masih belum optimal. Salah satu upaya untuk meningkatkan hasil dan mutu jagung manis dapat dilakukan dengan usaha manajemen kultur teknis diantaranya dengan pemberian pupuk kandang ayam dan kalium yang seimbang dan sesuai dengan kebutuhan sehingga hara tersedia bagi tanaman. Berdasarkan hal diatas perlu dilakukan penelitian untuk mengetahui pengaruh pupuk kandang ayam dan kalium terhadap hasil dan mutu jagung manis.

\section{BAHAN DAN METODE}

Penelitian ini dilaksanakan dikebun percobaan Fakultas Pertanian Universitas Islam Sumatera Utara (UISU) Medan pada jenis tanah ultisol dengan ketinggian $\pm 25 \mathrm{~m} \mathrm{dpl}$, dari bulan Agustus sampai dengan Nopember 2012. Bahan yang digunakan pada percobaan ini adalah benih jagung manis hibrida Sugar 75 produksi PT. Syngenta Indonesia, pupuk kandang ayam, pupuk kalium dalam bentuk $\mathrm{KCl}\left(60 \% \mathrm{~K}_{2} \mathrm{O}\right)$, fungisida Acrobat $50 \mathrm{WP}$ dan insektisida Matador 25 EC. Percobaan ini menggunakan Rancangan Acak Kelompok faktorial dengan 2 faktor perlakuan dan 3 ulangan. Faktor pertama adalah pupuk kandang ayam terdiri atas $A_{0}(0 \mathrm{Kg} / \mathrm{ha}), \mathrm{A}_{1}(10 \mathrm{Kg} / \mathrm{ha}), \mathrm{A}_{2}$ (15 $\mathrm{Kg} / \mathrm{ha})$ dan $\mathrm{A}_{3}(20 \mathrm{Kg} / \mathrm{ha})$. Faktor kedua adalah pupuk kalium terdiri dari $\mathrm{K}_{0}(0$ $\mathrm{Kg} \mathrm{K}_{2} \mathrm{O} / \mathrm{ha}$ ), $\mathrm{K}_{1}\left(90 \mathrm{Kg} \mathrm{K}_{2} \mathrm{O} / \mathrm{ha}\right), \mathrm{K}_{2}(120$ $\left.\mathrm{Kg} \mathrm{K}_{2} \mathrm{O} / \mathrm{ha}\right)$, dan $\mathrm{K}_{3}\left(150 \mathrm{Kg} \mathrm{K}_{2} \mathrm{O} / \mathrm{ha}\right)$.

Areal tanam dibabat dan dibersihkan dari sisa-sisa tanaman yang mengganggu, kemudian tanah dicangkul sekaligus membuat petak percobaan dengan ukuran $2 \times 3 \mathrm{~m}$. Jarak antar petak $50 \mathrm{~cm}$ serta jarak antar ulangan $1 \mathrm{~m}$. Benih yang akan ditanam, terlebih dahulu dilakukan seed treatment dengan merendam benih jagung manis dalam larutan fungisida Acrobat $50 \mathrm{WP}$ dengan konsentrasi 2 gr/liter air, tujuannya untuk mencegah serangan penyakit bulai yang disebabkan oleh jamur Peronosclerospora maydis. Setelah itu benih ditanam dengan cara menugal sedalam $5 \mathrm{~cm}$, kemudian diisi dua benih jagung manis pada setiap lubang dengan jarak tanam 50x30 cm. Setelah tanaman berumur 2 minggu dilakukan penjarangan dengan meninggalkan satu tanaman yang vigor setiap lubang. Pupuk kalium dan pupuk kandang ayam diberikan sesuai dengan takaran yang telah ditetapkan. Aplikasi pupuk kandang ayam dilakukan 2 minggu sebelum tanam, sedangkan kalium diberikan 3 kali, 1/3 bagian diberikan pada umur 2 minggu setelah tanam, 1/3 bagian diberikan pada umur 30 hari setelah tanam dan $1 / 3$ bagian lagi diberikan pada umur 45 hari setelah tanam. Cara pemberian dilakukan dengan cara menanam disamping tanaman dengan jarak $5 \mathrm{~cm}$. Untuk memberikan ruang tumbuh yang lebih baik bagi tanaman, dilakukan pemeliharaan mencakup penyulaman, penyiraman, pengendalian hama dan penyakit serta pengendalian gulma. Peubah amatan meliputi bobot tongkol, serapan kalium, kadar kalium dalam jaringan, indeks panen dan kadar gula.

\section{HASIL DAN PEMBAHASAN}

Berdasarkan data dan hasil
penelitian yang telah dilakukan
menunjukkan bahwa perlakuan pupuk
kandang ayam dan pupuk kalium secara
statistik tidak memberikan pengaruh
nyata terhadap bobot tongkol, serapan
kalium, kadar kalium dalam jaringan,
indeks panen dan kadar gula, seperti
disajikan pada Tabel 1 dan Tabel 2 .

Berdasarkan data dan hasil penelitian yang telah dilakukan menunjukkan bahwa perlakuan pupuk kandang ayam dan pupuk kalium secara statistik tidak memberikan pengaruh nyata terhadap bobot tongkol, serapan kalium, kadar kalium dalam jaringan, disajikan pada Tabel 1 dan Tabel 2. 
Tabel 1. Bobot tongkol, indeks panen dan kadar gula Jagung manis dengan perlakuan pupuk kandang ayam dan kalium

\begin{tabular}{|c|c|c|c|c|}
\hline \multirow{2}{*}{$\begin{array}{l}\text { Perlakuan } \\
\text { Pupuk kandang } \\
\text { ayam } \\
\text {----- kg/ha ----- }\end{array}$} & \multirow[b]{2}{*}{$\begin{array}{l}\text { Kalium }\left(\mathrm{K}_{2} \mathrm{O}\right) \\
---\mathrm{kg} / \mathrm{ha}--\end{array}$} & \multicolumn{3}{|c|}{ Peubah yang diamati } \\
\hline & & $\begin{array}{l}\text { Bobot } \\
\text { tongkol } \\
---- \text { gr ----- }\end{array}$ & $\begin{array}{l}\text { Indeks panen } \\
---\% \text {---- }\end{array}$ & $\begin{array}{l}\text { Kadar gula } \\
----\% \text {--- }\end{array}$ \\
\hline 0 & 0 & 187.77 & 55.77 & 10.23 \\
\hline 0 & 90 & 212.80 & 59.94 & 5.54 \\
\hline 0 & 120 & 249.30 & 63.45 & 18.22 \\
\hline 0 & 150 & 219.63 & 60.22 & 13.03 \\
\hline 10 & 0 & 183.40 & 56.52 & 9.57 \\
\hline 10 & 90 & 222.30 & 58.31 & 8.64 \\
\hline 10 & 120 & 211.30 & 62.31 & 10.29 \\
\hline 10 & 150 & 211.03 & 58.65 & 11.59 \\
\hline 15 & 0 & 195.37 & 58.86 & 7.98 \\
\hline 15 & 90 & 198.57 & 57.40 & 12.76 \\
\hline 15 & 120 & 206.20 & 60.13 & 8.64 \\
\hline 15 & 150 & 177.17 & 58.41 & 10.08 \\
\hline 20 & 0 & 242.47 & 58.21 & 7.72 \\
\hline 20 & 90 & 184.13 & 60.32 & 13.36 \\
\hline 20 & 120 & 202.63 & 59.11 & 11.97 \\
\hline 20 & 150 & 196.50 & 58.70 & 8.21 \\
\hline
\end{tabular}

Keterangan: Angka yang diukuti oleh huruf yang sama pada kolom yang sama tidak berbeda nyata pada taraf 5\% berdasarkan uji Duncan

Tabel 2. Serapan kalium dan kadar kalium dalam jaringan tanaman Jagung manis dengan perlakuan pupuk kandang ayam dan kalium

\begin{tabular}{llll}
\hline Perlakuan & & Peubah yang diamati \\
\hline Pupuk kandang ayam & Kalium $\left(\mathrm{K}_{2} \mathrm{O}\right)$ & Serapan kalium & Kadar kalium \\
$-----\mathrm{kg} / \mathrm{ha}$----- & $-----\mathrm{kg} / \mathrm{ha}-----$ & $-----\mathrm{mg}$----- & ---- \% ----- \\
\hline 0 & 0 & 151.06 & 7.39 \\
0 & 90 & 141.53 & 7.07 \\
0 & 120 & 144.46 & 7.06 \\
0 & 150 & 143.15 & 7.00 \\
\hline 10 & 0 & 139.40 & 6.82 \\
10 & 90 & 158.37 & 7.74 \\
10 & 120 & 125.87 & 6.16 \\
10 & 150 & 148.56 & 7.26 \\
\hline 15 & 0 & 139.05 & 6.80 \\
15 & 90 & 146.03 & 7.14 \\
15 & 120 & 137.87 & 6.74 \\
15 & 150 & 126.16 & 6.17 \\
\hline 20 & 0 & 151.61 & 7.41 \\
20 & 90 & 121.57 & 5.94 \\
20 & 120 & 136.49 & 6.67 \\
20 & 150 & 158.86 & 7.77 \\
\hline
\end{tabular}

Keterangan : Angka yang diukuti oleh huruf yang sama pada kolom yang sama tidak berbeda nyata pada taraf 5\% berdasarkan uji Duncan 
Dari Tabel 1 dan Tabel 2 dapat diketahui bahwa aplikasi pupuk kandang ayam dan kalium tidak menunjukkan respon signifikan terhadap semua parameter yang diamati. namun terdapat kecenderungan hasil dan mutu jagung manis meningkat sejalan dengan penambahan kalium.

Bobot tongkol, indeks panen dan kadar gula tertinggi dijumpai pada perlakuan $\mathrm{A}_{0} \mathrm{~K}_{2}$. Sedangkan serapan kalium dan kadar kalium dalam jaringan tertinggi dijumpai pada perlakuan $\mathrm{A}_{3} \mathrm{~K}_{3}$. Kondisi ini diduga akibat dari sifat kimia tanah pada lokasi penelitian memiliki tingkat kesuburan kimia yang rendah. Hal ini terlihat dari hasil analisis tanah, yang mana $\mathrm{pH}$ tanah berada pada kriteria masam, yakni 5.37, N-total tanah rendah yakni $0,11 \%$, kandungan $\mathrm{P}_{2} \mathrm{O}_{5}$ sedang yakni 20.18 dan K-dd 0.15 serta $\mathrm{K}_{2} \mathrm{O}$ 0.01 termasuk dalam kriteria sangat rendah. Rendahnya tingkat kesuburan tanah yang terdapat pada lokasi penelitian ini dikarenakan tanah ini tergolong dalam jenis tanah ultisol yang merupakan tanah mineral masam yang telah mengalami pelapukan lanjut. Disamping itu curah hujan dilokasi penelitian termasuk tinggi, sehingga selain mengakibatkan tanah menjadi masam juga terjadi pencucian unsur hara terutama hara yang kelarutannya tinggi seperti nitrogen dan kalium. Berdasarkan keadaaan tersebut maka pemberian kalium belum dapat diserap secara optimal sehingga belum menunjukkan respon signifikan. Kondisi curah hujan dilokasi penelitian selama 6 bulan disajikan pada Tabel 3 .

Tabel 3. Data Curah Hujan Bulanan Stasiun Badan Meteorologi Klimatologi dan Geofisika Medan Polonia Tahun 2012

Curah Hujan/Bulan

\begin{tabular}{llllll}
\hline Juli & Agustus & September & Oktober & November & Desember \\
\hline 278.8 & 160.2 & 255.3 & 333.8 & 234.8 & 270.2
\end{tabular}

Sumber : BMKG Polonia Medan, 2012

Dari Tabel 3 dapat diketahui bahwa curah hujan pada waktu penelitian dilaksanakan tergolong tinggi yakni lebih besar dari $200 \mathrm{~mm} / \mathrm{bulan}$. Keadaan ini memberikan dampak negatif terhadap pertumbuhan jagung karena dapat menimbulkan kejenuhan akar serta mengakibatkan terjadinya pencucian unsur hara terutama nitrogen dan kalium sehingga ketersediaan bagi tanaman menjadi rendah. Hal ini sejalan dengan pernyataan Putra, et al (2010), kehilangan kalium akibat pencucian dan erosi cukup besar sehingga menganggu pertumbuhan tanaman. Selain itu, air yang berlebihan dapat mengubah berbagai proses kimia dan biologis dalam tanah yang membatasi jumlah oksigen sehingga akar jagung tidak dapat melaksanakan respirasi normal aerob tetapi terjadi respirasi anaerob. Keadaan seperti ini akan dapat mengganggu pertumbuhan jagung manis (Tjingor's, 2009).

Rendahnya status hara $\mathrm{K}_{2} \mathrm{O}$ $(0.01 \%)$, K- dd (0.15 me/100g) memberi pengaruh terhadap pertumbuhan jagung manis. Status hara $\mathrm{K}$ yang rendah mengakibatkan pemberian kalium belum optimal sehingga tanaman tidak menunjukkan respons yang signifikan secara statistik terhadap semua parameter yang diamati. Berkaitan dengan hal ini, Wang et all (2013) mengemukakan bahwa kalium 
berperan penting dalam fotosintesis, karena secara langsung meningkatkan pertumbuhan, memperluas pertumbuhan akar dan Luas Daun. Selain itu rendahnya status hara nitrogen yakni $0,11 \%$ juga berdampak terhadap pertumbuhan jagung manis. Berkaitan dengan keberadaan unsur nitrogen, Liferdi (2010) dan Laude dan Tambing (2010) mengemukakan bahwa manfaat dari nitrogen adalah untuk memacu pertumbuhan tanaman pada fase vegetatif, serta berperan dalam pembentukan klorofil, asam amino, lemak, enzim, dan persenyawaan lain. Hal senada juga dikemukakan Pranata (2010) bahwa zat hijau daun yang terbentuk oleh nitrogen berperan membantu proses fotosintesis. Proses immobilisasi nitrogen dan kalium menunjukkan bahwa unsur hara tersebut belum tersedia dalam jumlah yang cukup didalam tanah sehingga menghambat pertumbuhan, hasil dan mutu jagung manis.

Ketersediaan hara makro utama dalam tanah sangat ditentukan oleh $\mathrm{pH}$ yang mana nitrogen tersedia pada $\mathrm{pH}$ $5.5-8.5$, fosfor pada $\mathrm{pH} 5.5-7.5$ sedangkan K pada pH 5.5 - 10 (Mirza, 2013). Untuk menunjang pertumbuhan dan produksi, tanaman membutuhkan suplai hara yang cukup selama pertumbuhannya.

\section{KESIMPULAN}

Pemberian pupuk kandang ayam dan kalium belum menunjukkan pengaruh signifikan terhadap peningkatan hasil dan mutu jagung manis, namun terdapat kecenderungan peningkatan hasil dan mutu jagung manis sejalan dengan penambahan kalium.

\section{DAFTAR PUSTAKA}

Budiastuti, M.S., D. Suroto, dan S. Haryanti. 2011. Penggunaan Glifosat dan Macam Olah Tanah pada Pertanaman Jagung Manis. Konfrensi Nasional XV HIGI di Surakarta.

Liferdi, L., 2010. Efek Nitrogen Terhadap Pertumbuhan dan Produksi Tanaman Manggis (Garcinia mangostana L). Prosiding : Seminar Nasional Program dan Strategi Pengembangan Buah Nusantara Balitbu Tropika, Solok.

Listyobudi, V.R. 2011. Perlakuan Herbisida pada Sistem Tanpa Olah Tanah Terhadap Pertumbuhan, Hasil dan Kualitas Hasil Tanaman Jagung Manis (Zea Mays Sacharata, STURT). Tesis Pasca Sarjana Prodi Agroekoteknologi. UPN Veteran Yogyakarta.

Mirza, M.F., 2013. Hara dan Hubungannya dengan Tanaman. http://laborrilmu.blogspot.com. (Diakses 19 Agustus 2014).

Pranata A S. 2010. Meningkatkan Hasil Panen Dengan Pupuk Organik. Agromedia Pustaka, Jakarta. $146 \mathrm{hlm}$.

Putra, I.A., Hanum, H., Hanum.C, 2010. Pengelolaan Hara Kalium Berdasarkan Batas Kritis Untuk Tanaman Jagung (Zea mays L.) Pada Berbagai Status Hara di Tanah Inceptisol. Tesis Pasca Sarjana Prodi Agroekoteknologi. USU

Tjingor's. M, 2009. Esensialitas Air Bagi Pertumbuhan dan Produksi Tanaman Jagung Manis. 
http://desain.blogspot.com.

(Diakses 19 Maret 2012).

Wang Min, Qingsong Zheng, Qirong

Shen, and Shiwei Guo (2013)
The Critical Role of Potassium in Plant Stress Response. Int J Mol Sci 14:7370-7390 